\title{
Copyright and Digital Collections: A Data-Driven Roadmap for Rights Statement Success
}

\section{Sara R. Benson and Hannah Stitzlein}

\begin{abstract}
An earlier version of this manuscript was presented by the authors at the biennial conference of the Association of College and Research Libraries, April 13, 2019. The authors wish to acknowledge the Research and Publication Committee of the University of Illinois at Urbana-Champaign Library, which provided support for the completion of this research. We would also like to thank Janet Swatscheno, the Digital Publishing Librarian at the University of Illinois Chicago, for her helpful comments on an earlier draft of this article.
\end{abstract}

This article summarizes the results of interviews with Digital Public Library of America (DPLA) service hub participants to determine whether and how standardized rights metadata is included in their digital collections. Providing accurate standardized rights metadata is crucial to communicating with patrons regarding how they can use objects in digital collections. Results from the interviews reveal key findings on effective rights statement implementation techniques as well as common tools used by librarians when applying rights statements to digital collections.

\section{Introduction}

Standardized rights statements and licenses are relatively recent developments for digital collections and institutional repositories, with Creative Commons licenses debuting in 2001 and RightsStatements.org originating much more recently in 2015. Standardized rights statements are a set of interoperable standardized statements for digital collections designed to provide patrons with information about the rights status of digital objects in a more consistent fashion. Currently, there are 12 distinct statements "that can be used by cultural heritage institutions to communicate the copyright and re-use status of a digital object to the public." ${ }^{1}$ Using standardized rights statements in digital collections conveys to users how they may interact with digital items, but determining the correct rights statement is not always straightforward. An analysis of rights statements in digital collection metadata from the DPLA Illinois service hub participants in 2017 was at odds with the high levels of confidence self-reported in a 2016 librarian copyright knowledge survey in which the Illinois hub found that only 25 percent of the metadata in the rights field included any information about copyright. ${ }^{2}$

Sara R. Benson is Copyright Librarian at the University of Illinois at Urbana-Champaign; email: srbenson@illinois.edu. Hannah Stitzlein is the Document Manager for the World Trade Center Health Program at NIOSH; email:hevstitzlein@gmail.com. (2020 Sara R. Benson and Hannah Stitzlein, Attribution 4.0 International (https:// creativecommons.org/licenses/by/4.0/) CC BY-4.0. 
In 2016, the DPLA ${ }^{3}$ announced they would soon require the use of standardized rights statements. As a result, many DPLA hub participants began implementing the statements in their digital collections metadata or are currently in the process of preparing to do so, while others, who do not have the resources to begin implementation, are cognizant of the movement to implement standardized rights statements. Furthermore, due to this announcement, many of the newer DPLA hubs require any participating institution to include standardized rights statements in their digital collections. Due to the wide adoption of these statements within the DPLA hub community, the researchers had an ideal pool of candidates for semistructured interviews, as the community had a familiarity with the statements, and many were in some state of consideration of implementation.

The two questions that ultimately guided this research were: What are the challenges metadata practitioners face when implementing standardized rights statements? And, for institutions that have implemented standardized rights statements, what made them successful? The authors began the investigation to fill in the practical gaps of the previous studies, and to determine if barriers to implementing standardized rights statements were due to a lack of copyright knowledge and/or access to a copyright professional, or if there were resource barriers limiting the ability to begin implementation. Insights gained from this study will be useful for institutions developing their own workflows for implementing standardized rights statements.

\section{Literature Review}

In 2016, Saunders and Estell conducted a survey to assess the confidence levels of librarians with respect to knowledge of copyright and fair use. Survey respondents were asked to selfreport their copyright literacy levels. The study found that 95 percent of respondents ranked themselves as having "strong familiarity with Digital Institutional Repositories ... and copyright's role in digitization." ${ }^{4}$ Despite the reportedly high confidence of respondents to the study, many other studies demonstrate a discrepancy between the self-reported knowledge and the practical application of that knowledge. In an assessment of their digital collections, the Penn State Libraries found that a boilerplate statement was often used to describe digital objects, and 27 of the 65 collections at that institution had no rights statement in the item-level metadata. ${ }^{5}$ Using a boilerplate statement may communicate to users that the library has not undertaken the responsibility of making a rights determination of the specific content that has been digitized and made available online. This issue was also present in a study at the University of Miami, where practices for describing copyright in legacy metadata had evolved over the years, resulting in a myriad of rights statements. ${ }^{6}$ Capell and Williams found that "item-level copyright information had [previously] not been prioritized and, as a result, the University of Miami Libraries' digital collections contained an array of rights metadata that did not always provide useful or accurate information for researchers."

These three studies support the information reported in the whitepaper of the International Rights Statements Working Group for RightsStatements.org, which located more than 87,000 individual rights statements in DPLA alone at the time of review. ${ }^{8}$ This finding highlighted the need for standardization of the language in rights statements; as a result, 12 rights statements were developed by Europeana (an EU-based portal of digital collections in Europe) and the DPLA for international use. There are three categories each of the statements falls into: In Copyright, No Copyright, and Other-which covers undetermined, unevaluated, and no 
known copyright statuses. The lack of standardization in statements was an impetus for both DPLA and Europeana to create standardized rights statements because it "undermines the core mission of these cultural heritage institutions to "expand [the] crucial realm of openly available materials, and make those riches more easily discovered and more widely usable and used."'9

\section{Methodology}

Participants were recruited to participate in this qualitative interview study through an email directed to the DPLA service hub provider listserv members. The recruitment email requested participants to further distribute the call for participation to their DPLA hub member libraries. Thus, interview participants included both DPLA service hub providers (or organizations helping to aggregate large batches of digital collections metadata into the DPLA) as well as individual DPLA contributing institutions. This broad call for participation solicited the broadest possible mix of individuals working to implement rights statement metadata with DPLA digital materials, providing the point of view of implementation for multi-institutional organizations and individual institutions. Participants were informed that the interview would take approximately 30 minutes, be conducted by telephone, and be recorded for data analysis purposes. Participants were also informed that the purpose of the research was to better understand the workflows and current implementation of the Standardized Rights Statements. Only one person per institution was interviewed, except in two cases where two people were from the same library and were working as a team on their digital collections.

The basic interview questions, which were developed by the authors to best determine whether and how DPLA rights statements are currently being used by interview participants, are attached to this article as appendix A. The interviews were semistructured to allow for additional appropriate follow-up questions to be asked when necessary to identify further relevant data points.

The interviews were transcribed by an hourly graduate assistant and the transcriptions were uploaded into Atlas.ti-a qualitative analysis coding tool. Both researchers then independently coded the interviews using grounded coding principles and then compared their codes together for intercoder consistency. ${ }^{10}$ Once the codes were de-duplicated and any conflicting codes were resolved, the researchers analyzed the results looking for patterns among the respondents and topics discussed.

\section{Demographics}

A total of 19 interviews were conducted with 21 total interviewees (two interviews had more than one participant). Demographic information was collected from the interview participants, including the size and nature of the library (examples: liberal arts college, R1 university, nonprofit organization) in which the participant works, the role of the participant in the library, as well as the size and type of digital content the participating library collects. The demographic results are indicated in the charts below:

Of the nine academic libraries in table 1 , three institutions are large-sized institutions (1 private, 2 public), two

\begin{tabular}{|l|c|}
\hline \multicolumn{2}{|c|}{$\begin{array}{c}\text { TABLE } 1 \\
\text { Types of Institutions } \\
\text { Represented in Interviews }\end{array}$} \\
\hline Institution Type & Total \\
\hline Academic Library & 9 \\
\hline Consortium & 3 \\
\hline Public Library & 3 \\
\hline Nonprofit & 2 \\
\hline Research Library & 1 \\
\hline State Library & 1 \\
\hline
\end{tabular}


are medium-sized institutions (1 public, 1 private), and four are small, private institutions. The size of the institution was determined by the Carnegie Classification of Institutions. The three institutions that identify as a consortium oversee public and academic libraries, as well as historical societies and research libraries. One public library identified as a large metropolitan public library serving a population of more than 800,000 , and two public libraries identified as mid-size metropolitan libraries serving populations between 100,000 and 200,000.

In addition to the totals in table 2, all libraries indicated that the number of reported digital objects were from a mix of cultural heritage digital collections and institutional repositories holding scholarly materials. Many institutions did not differentiate between the two types of digital content when discussing the totals of digital items in their collections.

Respondents fell into six categories (see table 3) for roles performed at their respective institutions. All respondents identified as a librarian or archivist with varying degrees of title, demonstrating the variety of individuals at different institutions tasked with providing rights metadata for digital collections.

\section{Analysis of Interview Data}

After having transcribed and coded the data, the

\begin{tabular}{|l|c|}
\hline \multicolumn{1}{|c|}{$\begin{array}{c}\text { TABLE } 2 \\
\text { Number of Items in Institutional } \\
\text { Digital Collections }\end{array}$} \\
\hline $\begin{array}{l}\text { Number of Items in } \\
\text { Collection }\end{array}$ & $\begin{array}{c}\text { Number of } \\
\text { Institutions }\end{array}$ \\
\hline Under 1,000 & 2 \\
\hline $1,000-5,000$ & 2 \\
\hline $5,001-10,000$ & 5 \\
\hline $10,001-20,000$ & 2 \\
\hline $20,001-30,000$ & 2 \\
\hline $30,001-50,000$ & 1 \\
\hline $50,001-100,000$ & 1 \\
\hline $100,001-500,000$ & 1 \\
\hline Over 500,000 & 3 \\
\hline
\end{tabular}

\begin{tabular}{|l|c|}
\hline \multicolumn{2}{|c|}{$\begin{array}{c}\text { TABLE 3 } \\
\text { Respondent Roles at Each } \\
\text { Institution }\end{array}$} \\
\hline Interviewee Role & Total \\
\hline Digital Projects Manager & 6 \\
\hline Archivist & 5 \\
\hline Digital Services Librarian & 4 \\
\hline Metadata Librarian & 3 \\
\hline Director & 2 \\
\hline Other & 1 \\
\hline
\end{tabular}
authors noticed a pattern of significance across the different interviews. Issues surrounding copyright included a lack of copyright knowledge, copyright uncertainty, risk assessment issues, and local copyright practices in rights implementation. Challenges relating to rights implementation included whether the institution prioritizes implementation, structural challenges, staffing and time challenges and whether the institution has access to copyright professionals. Each of these topics will be discussed in turn below.

\section{Copyright Challenges}

To accurately assign rights statements to the metadata of digital objects, a proficient knowledge of copyright rules is ideal. For instance, if a librarian assigning rights statements to digital objects did not know that the public domain expanded on January 1, 2019, the librarian might incorrectly assume that works were still in copyright when perhaps they are not. Such mistakes are at first glance innocent and free of malice; however, on a large scale, these errors misinform library patrons and contribute to copyfraud - or the incorrect assertion to the public that a particular digital work is copyright restricted when it is actually in the public domain. ${ }^{11}$ Falsely claiming copyright ownership for public domain images can result in a lawsuit as well. ${ }^{12}$ Thus, in designing the evaluative measures for this research project, the 
investigators chose to incorporate a baseline copyright knowledge question (see appendix, Q12) to determine whether the participants understood a specific basic copyright concept.

To further test these self-assessments, the investigators asked a more specific copyright knowledge question to interview participants. Interview participants were asked: "In their understanding, do physical and digital objects have the same copyright status?" (see appendix, Q12) Respondents were further instructed to determine, when a librarian scans a newspaper article, whether the physical newspaper and the digital object have the same copyright status. This particular question was used because it has a simple, uncontroversial answer. Relying on case law, the answer should be "yes" because the digital object is just a slavish rendition of the original object - in other words, the copy lacks originality and therefore does not obtain its own copyright status. ${ }^{13}$ Furthermore, the example of a newspaper was used in this instance to delineate between three-dimensional and two-dimensional objects, where there may be some debate about the "correct" answer to this question. ${ }^{14}$

Although the sample size was small for the interviews, the specific question and answer allowed for a more nuanced assessment of the copyright knowledge of the participants. In the interviews, four of the 21 participants (or 19\%) incorrectly stated that the copyright statuses of the two objects were distinct. Some qualified their answer by noting that, although the digital copy created a new copyright, the library would not assert copyright over the digital file. Other participants noted that they had previously believed this to be true (the digital file had a new copyright status) but through continuing education, they learned that this was not the case. Yet others, even when they answered correctly, seemed to second-guess their response and seek clarification or assurance from the interviewers. Although only four participants were incorrect about this baseline copyright understanding, this particular copyright principle is crucial when assigning rights statements because if a library asserts a "digital copyright" over an otherwise slavish copy, copyfraud results. In that instance, patrons accessing the digital work will be led to believe that it is still protected by copyright when, in fact, the work is in the public domain. This could stop patrons from using the work for their own research, publications, or any other purpose and is antithetical to the mission of the field of librarianship: to provide unfettered access to library holdings.

In addition to the insecurity of the answers to the previous question about the copyright status of a digitized object, the interviews further yielded a relatively high incidence of copyright uncertainty and the need for clarification in a few key areas detailed below in descending order from most to least frequently mentioned by interviewees:

- Orphan Works (mentioned by 4 participants)

- Deed of Gift Legacy Issues (3)

- Other Legal Issues, such as Privacy (3)

- Layers of Copyright (2)

- Publication Status of the Work (1)

- International Copyright (1)

Four participants mentioned the challenge of addressing orphan works in rights metadata. It is not surprising that those implementing rights statements would struggle with handling orphan works as even the US Copyright Office has been researching how best to address the challenges of managing such works. ${ }^{15}$ Similarly, legislation has been proposed (although not adopted) in the US House of Representatives to address such issues. ${ }^{16}$ Guidance (similar to that provided by the European Union) ${ }^{17}$ regarding how to adequately document a diligent search 
for the copyright owner of the work and the failure of such efforts would be a step toward meeting the challenge of digitizing orphan works. Orphan works often plague archives due to a lack of documentation on materials such as photographs where the creator is unidentified. Furthermore, determining the publication status of a work accessioned by an archive can similarly be unknown.

One respondent, who works for a nonprofit entity that has changed ownership and names multiple times, said there was no formal documentation of a transfer of rights or intellectual property from previous entities to the organization as it exists today. While they own the material and are responsible for it, many of those works have fallen into the realm of orphan works because of this situation. ${ }^{18}$

Three participants mentioned issues with older collections and problematic or nonexistent deeds of gift. In some cases, the deed of gift could not be located, there was no deed of gift, or the language in the deed of gift was problematic in that it did not clearly indicate a transfer of copyright. One library had a novel solution to this problem in its current deed of gift language in which it not only asked for a copyright transfer but for the permission to digitize the accompanying work. Where the copyright was not transferred to the library, the form gave the option to the copyright holder whether the digital work could be made available for only noncommercial uses, any kind of reuse, or no reuse except with express permission of the copyright owner. Additionally, if a transfer to the library was not agreed upon, then there was a negotiation of the quality of the access file made available to the public.

Accurate copyright grant language was not regularly included in the deeds of gift of participating institutions, and one respondent said that in their 20 years of work with the archives, only once was copyright expressed in a deed of gift. ${ }^{19}$ Another respondent said that a collection donated from the city did not have a donor agreement at all, which left many unanswered questions about the works. ${ }^{20}$

Three participants mentioned that they struggle not only with copyright, but with other legal issues when determining how to apply rights statements to digital works. One issue to consider is whether the work should be widely disseminated due to privacy concerns. Other legal and ethical issues also include federal statutes (such as FOIA or HIPAA) that protect student health information or university policies (especially relating to legacy collections of archival materials from campus). One interview participant noted that there are issues with ownership of microfilm relating to the organization that sold the library the microfilm asserting ownership over the copyright. ${ }^{21}$

A given work can involve multiple layers of copyright. For instance, in a published court case, the United States Postal Service asked for permission from the creator of a photograph of a famous sculpture to put the sculpture on US postal stamps. ${ }^{22}$ What the postal service failed to do, however, was to obtain permission to feature the sculpture on the stamps from the creator of the sculpture itself. In that way, the Postal Service violated copyright by failing to recognize that there were multiple layers of copyright involved (in other words, the "author" or copyright owner of the photograph as well as the "author" of the sculpture). ${ }^{23}$ Inserts into other materials, such as photographs owned by multiple authors included in a book, may also be subject to the problem of layers of copyright. While the book itself may be in the public domain, for instance, the photographs included in the book may not. ${ }^{24}$ At least two interview participants noted that they, too, struggle with layers of copyright when determining how to 
apply rights statements to digital works. For instance, one participant noted that they were "a little bit unsure about [the] copyright status of photographs of outdoor murals." 25

One interview participant mentioned that they struggled with determining whether a work would be considered published or unpublished for copyright purposes. It is often difficult to determine whether a given work would be considered published under the Copyright Act, especially before the 1976 Act when the term "published" was defined by case law. ${ }^{26}$ Even after 1976, with a definition of the term established, a given work "may be an earlier instance of a published work" and require further investigation. ${ }^{27}$

One interview participant discussed issues involving complications arising under international copyright law. The Society of American Archivists lists 1835 as the likely date for works to have entered the public domain internationally, as the longest known copyright is that of Mexico dating 100 years from the death of the author. ${ }^{28}$ If the author is assumed to have lived about 80 years, then subtracting 180 from 2015 (which is likely when this was calculated) yields the year 1835. Given that the year is now 2019, at least one librarian interviewed wondered whether this date should be recalculated to 1839 .

A large part of digitizing collections is assessing risk associated with making the collections available to the wider public in an online platform. However, despite the fact that risk assessment should necessarily be part of the process, the way that libraries and museums assess risk is often not transparent to those outside the library As such, the investigators sought to discover how librarians working with digitization define the term "risk assessment" to better understand how - or if - individuals making decisions about digital collections assess risk.

All of the participants viewed risk assessment principally through the lens of copyright law. In other words, they mentioned that they assess risk primarily by thinking about whether there would be a copyright owner who would object to the digital distribution of their work without express permission to do so. Another common theme addressed by participants was the level of comfort the organization had with being sued or taken to court for digitizing copyrighted materials without permission to do so. Most organizations were comfortable with low risk in that regard.

Participants also frequently mentioned that they mitigate against these risks in a variety of ways, including the following:

- Low-Risk Collections: public domain materials, collections for which they have permission to digitize, very old collections where the risk of receiving a copyright notice is low

- Takedown Policies: participants mentioned that they would readily take down collections where a copyright holder emerged with a complaint about the collection to avoid litigation

- Due Diligence: participants mentioned that they would use copyright checklists, fair use checklists, and attempts to locate or contact copyright holders (or demonstrate that the work is an orphan work) in good faith

Most participants mentioned the fact that they prioritize low-risk collections when digitizing works. However, a few participants were bolder. One librarian stated that their organization had a "pretty high" comfort level with "releasing ...things and letting people use them." ${ }^{29}$ Another stated that, although they "might not know the copyright status or who the holders are" for a given collection, they might put it "online anyway because of research value in putting it out there." 30 
Interview participants had many different local processes for determining the appropriate rights status of digital works. However, some were more notable for local procedures that were established and might be useful on a broader scale.

For instance, one interview participant mentioned that their copyright review process for collections involves an Excel spreadsheet where they import data "that are easily sortable by year, author, year of publication, year of creation, author birth and death dates if we have them, and any other information in the discovery metadata for the items." 31 This spreadsheet is then reviewed by librarians in a tiered process whereby only the questionable copyright items are pursued in more depth. Some examples of such questionable items include items where they need to inquire into the copyright renewal or other issues that could involve intervention by a copyright advisor or campus general counsel.

Similarly, another library uses a "matrix" contained in a spreadsheet that asks the librarian to input data column by column. One column, for instance, asks whether the item is considered published or unpublished. If the object is published, the next step is to input the country of origin of the work. Alternately, the next step for an unpublished work asks the death date of the work's author. The matrix steps will help guide the librarian toward selecting an appropriate rights statement to include in the metadata of a digital object.

Another participant who worked with multiple organizations, operating like a hub for the ingestion of DPLA materials, mentioned that they like to use a "hidden free text field" to describe how the copyright status on a particular item was determined. This field, which is intended for internal use, carries important information about due diligence in tracking down copyright status of the work and also includes key information about when copyright will expire. For instance, in this field, they include information on the "last year" that the given item will be in copyright so that the status of the work can be changed to the public domain when that time period expires on January 1 of a given year. At this point, however, those changes would need to be entered manually. ${ }^{32}$

\section{Implementation Challenges}

Libraries, archives, museums, and other cultural heritage institutions increasingly understand the benefit to using standardized rights statements (such as consistent language, correct legal terminology, linked data capabilities); but, in spite of the desire to implement standardized rights statements, there are barriers that complicate or altogether hinder this process. Certainly, there are the intangible issues of the time and staff it requires to accurately assess the rights of each collection, but there are also more practical aspects of implementing rights metadata that can be challenging. Other challenges include legacy issues with both the content management system - used for displaying digital content-as well as old metadata that may have been added when different, or nonexistent, best practices were in place. Another issue that was discussed by participants was the concern of buy-in from local administration, without which moving forward with implementation was unattainable.

Interview participants described their content management systems (CMS) - CONTENT$\mathrm{dm}$, LUNA, Omeka, and DSpace - as a significant hindrance to implementation. One of the issues noted is the lack of uniform resource identifier (URI) support in the various systems. Both RightsStatements.org and Creative Commons rely on the use of URIs to link to the full language associated with each rights statement ${ }^{33}$ or license, ${ }^{34}$ respectively, and without URI support, digital collection creators are left to piece together workarounds that do not align 
with best practices. After analyzing the standardized rights statements, one organization determined that the length of the statements was prohibitive because "it just would look bad on the screen to users." ${ }^{35}$ If implemented correctly, however, the entirety of the language of the rights statement would not be viewed in the digital collection platform; rather, each item would link to the full language of the statement with the URI. For this respondent, and for many others, the content platform they use (for example, CONTENTdm) does not currently support URIs, which results in less than optimal implementation.

Batch-editing content in some systems was another limiting factor for implementation. Some systems, such as CONTENTdm, have built-in batch-editing tools, which is useful for homogeneous collections where the copyright status is the same for all items, or when consistent language was used for previous descriptions of copyright. However, variation in language can make the built-in batch-editing tools nearly useless. One participant's method for overcoming this challenge was to batch-edit outside the CMS by importing metadata into OpenRefine ${ }^{36}$ where they could group legacy rights statements that had similar but inconsistent rights language describing the same rights status. After grouping similar statuses, the rights statuses could be updated with the URI and the label for the standardized rights statement. However, if a CMS does not allow batch-importing of metadata, the alternative may be tedious metadata editing for each individual digital object.

The issue of inconsistent language was often attributed to practices no longer in use, while the absence of any rights statement was often attributed to having incomplete archival intake paperwork that failed to address rights and licensing at the time. Many participants described their frustrations with these situations, and two declared that the ability to go back in time to adjust these practices and paperwork would be especially helpful to their current practice. While the authors are not able to provide any insight on time travel, these desires do point to the benefit of using standardized rights statements for the sake of future metadata practitioners and collection developers. By using consistent, standardized language, batchediting metadata is an attainable goal.

The value of priorities for describing copyright accurately in digital collections varied among participants. Describing copyright accurately directly corresponded to whether or not a boilerplate statement was used. In other words, the four participants who incorrectly stated that the library owned a copyright in the slavish reproduction of a newspaper (examined above) were the same libraries that included boilerplate statements with their digital collections. One respondent said, "For us in particular, it's not much of a priority because we just have the blanket statement [that says] 'Copyright holder unknown,' which isn't always the case." However, accurately describing copyright was a significantly higher priority for institutions that apply individual rights statements and have a more critical approach to applying rights statements. Priority of accurate rights description primarily tended to be driven by the fear of being sued.

Buy-in was described as a key component for moving forward, both at the administrative level and among collection owners. One respondent said they did not feel that they had the clout on campus to engage with the library administration to consider methods that would facilitate better practices for rights management and standardization implementation. Another respondent said that their institution legal department was a substantial barrier to local buyin from administrators.

When asked what would make copyright accuracy a priority, one respondent said, "Resources, really. If we could justify [having] someone whose position was primarily working 
with rights and copyright," it would go a long way to ensure accuracy of the copyright information. ${ }^{37}$ Another respondent said that copyright accuracy was important "just to be accurate from an archiving and information management perspective, but also from an institutional perspective-we want to be responsibly releasing this material." 38

When speaking to interview participants, 47 percent stated that the biggest challenge is copyright determination for materials intended to be made available online, 26 percent said that getting permissions from copyright holders is a significant issue, and only a small number $(16 \%)$ of participants said that time is a major barrier to implementation. Others cited local buy-in - both from administrators and collection owners - as a major obstacle, as well as staffing, while one respondent stated that they had no challenges in implementing standardized rights statements.

"My boss would have to think this is a priority, and then lead the charge in that direction," one respondent said. ${ }^{39}$ Several respondents felt that someone in a higher position than they would need to be convinced of the value of using standardized rights statements before implementation was an option. One interviewee said that using standardized rights seemed straightforward, but that buy-in from library stakeholders was what was holding them back from implementation.

Seven interview participants mentioned that their biggest challenge with implementing rights statements is having the necessary staff and/or the time to do a thorough investigation into the copyright status of the digitized work, especially with legacy collections where the deed of gift may not be clear. More specifically, one participant wished there were a single person tasked with curating the online digital projects to make the statements more uniform, as opposed to projects completed by individuals who are only focused on a given collection.

A lack of time and staffing may also result in the use of boilerplate language. One interview participant noted that the value of using standardized rights statements did not outweigh the time it would take to change their current rights statement. They further explained that the current rights statement declared that the copyright holder was unknown, which the librarian said was not always true. Another participant said all of the items in their digital collections previously included a statement stating: "Images are provided for personal and educational use only ... and any use beyond that is up to the discretion of the user." ${ }^{\prime 40}$ But the participant further stated that this type of statement was not helpful to the users as it essentially told patrons "here's some stuff and we don't know anything about it or what you can do with it." ${ }^{41}$ This library would then receive calls from users who wanted to know how they could use an image, ultimately still involving staff time to research the copyright status and uses associated with a digital object. After implementing standardized rights statements, the library saw a drop in these calls as users had clear information about both the copyright status and use permissions.

Due to the numerous complicated copyright issues that arise in implementing rights statements for digital collections, access to a copyright professional, either an attorney or a copyright librarian, is a crucial resource for librarians. However, out of the nineteen institutions participating in the interviews, only two had access to a full-time staff member whose job included copyright specialization, such as a copyright librarian or copyright advisor. Four others had access to a member of the general counsel team of the institution for high-level copyright issues, while an additional two had access to an attorney or copyright librarian on an as-needed or hourly basis. These two respondents had resources for an hourly fund for 
an ask-a-lawyer service to consult with about complicated questions that arose in the library. The responses from the attorney were then filed for future use in an FAQ queue so that the library need not pay the attorney an additional fee if a similar question arose in the future. This seemed to be working fairly well for that particular institution and may serve as a model to institutions with funding available to put toward the management of legal issues (this library had allocated $\$ 4,500$ for this service and was intending to add more in the upcoming fiscal year), but not enough to hire a copyright librarian, for instance. ${ }^{42}$ Overall, this indicates that strong copyright education is necessary for those engaging in copyright metadata analysis because most frequently they must understand copyright and handle these issues independently. Similarly, a working group available to answer complicated questions on an as-needed basis would also be a helpful tool.

\section{A Roadmap for Success Workflows}

The authors gathered many examples from the interview participants for successful copyright determination and standardized rights statements applications workflows. The most efficient and successful workflows in the opinion of the authors when comparing the techniques described by the interview participants involved archival intake paperwork that addressed copyright and licensing, which relieved much of the problems that other institutions grappled with, particularly a lack of information to make accurate copyright determinations. One participant said that, as part of the agreement that donors sign, language about digitization is included to remove the need to contact donors at a later date to secure permissions to digitize. Another participant said they wished they could go back in time to make clearer gift agreements, which would make their current work much easier. A third participant said that, in their first two years in their position, their institution did not have any donor agreements; but they have since added donor agreements, which have evolved over time, and now include a section about rights and permissions. They went on to say that they are in the process of detangling the previous iterations but that having the rights and permissions clearly outlined in the donor agreement has helped immensely.

Other workflows that were particularly successful relied heavily on the use of tools as a means of copyright determination. There were several publicly accessible tools that were mentioned multiple times-and will be outlined below-while others were homegrown tools that were developed for local needs and practices. One of the benefits of using the tools is that it leads to more informed decision making, regardless of the institution's access to a copyright professional.

\section{Tools}

When asked about workflows, the interview participants universally cited tools and educational training that assisted them in making rights determinations for digital collections. Although these tools are each helpful, they are not a panacea. Many participants mentioned the need for face-to-face training, as well as the desire for a document detailing case examples of how to best apply the rights statements in both common and more complex scenarios.

By far, the most mentioned tool (mentioned by nine participants) was Peter Hirtle's Copyright Term and the Public Domain chart. ${ }^{43}$ It is unsurprising that this chart was mentioned so frequently, as it is a useful, highly accurate, visually clear chart for determining the legal 
rules applicable to a given time period in the United States. The chart breaks down copyright determination into published and unpublished works, and is an easy-to-read and endlessly useful tool.

The Society of American Archivists Guide to Implementing Rights Statements from RightsStatements.org ${ }^{44}$ and the PA Digital Rights Statement Selection Tool Flowchart by Gabriel Galson ${ }^{45}$ were mentioned by three participants each as being helpful when applying rights metadata. One organization involved in the arts mentioned the Code of Best Practices and Fair Use for the Visual Arts by the College Art Association. ${ }^{46}$ Finally, one organization has developed its own tool in the form of a spreadsheet for making rights determinations.

Another flowchart was recently developed to guide the librarian through a series of choices before making a determination for both the copyright status and whether to use one of the statements from RightsStatements.org or a license from Creative Commons: the Rights Review: An Approach to Applying Rights Statements from RightsStatements.org chart created by members of the Minnesota Digital Library. ${ }^{47}$ None of the participants mentioned this new flowchart, likely because it was brand-new at the time the interviews took place.

One tool that could be particularly useful to individuals struggling with the application of rights statements, as noted by an interview participant, is a case study document describing a particular challenging rights statement case as well as proposed solutions to the challenge.

\section{Conclusion}

This research demonstrates that, while there are some best practices for implementing rights statements, there is no one-size-fits-all approach. With each institution comes a myriad of possible workflows and tools that fit that institution's needs and staffing situations. It is important, for instance, to be current with appropriate rights statements by flagging collections and works that may enter the public domain in the near future and to update the rights statements at that time. While many librarians are working hard to update rights statements, legacy issues remain a challenge. Copyright issues when applying standardized rights statements are often complex, and copyright librarians are few, adding to the challenge for librarians adopting standardized rights statements.

However, for institutions that have implemented standardized rights statements successfully, some key areas of success include intake workflows that incorporate more specific information about the right to digitize the material, as well as the manner in which the material can be distributed. Similarly, the use of tools to aid in decision making regarding complex copyright determinations can be helpful to those implementing standardized rights statements.

Currently, many helpful tools are available to aid in the success of those wishing to begin implementing standardized rights statements. As more institutions aim for implementation, a greater variety of tools and checklists will likely be developed and shared among the metadata community. And the challenge of providing accurate rights information to users of digital collections will be met by thoughtful curators with the support of communities of practice. 


\section{APPENDIX. Rights Questions and Copyright}

1. Can you tell us about the institution that you work for and what your role is there? (R1? We will remove specifics, how large is it?)

2. What kind of digital collections do you work with? (such as size, type of collection [IR vs. $\mathrm{CHO}$ - cultural heritage objects], how many)

3A. Do you currently use standardized rights statements or Creative Commons licenses in your digital collections?

3B. If no, is there anything preventing you from implementing Standardized Rights Statements or Creative Commons Licenses? If so, what?

3C. What would you need to begin implementation?

4. Who makes copyright decisions for the digital collections?

5. How do you make rights determinations at your institution?

6. Can you describe the workflow for this process?

7. Do you have access to a copyright professional in this process?

8. What do you think are ideal components to a rights statement? What is important to include in a rights statement?

9. How much of a priority is accuracy in the rights field? What would assist in making it a more significant priority?

10. What do you understand risk assessment to mean regarding digital collections?

11. What kind of risk assessment, if any, do you engage in when determining whether to put collections online?

12. In your understanding of copyright, do physical and digital objects have the same copyright status?

13. What is the biggest copyright challenge you face when developing digital collections?

14. What is the biggest copyright challenge you face when adding rights information to digital collections? 


\section{Notes}

1. RightsStatements.org, “Rights Statements,” https://rightsstatements.org/page/1.0/?language=en [accessed November 6, 2019].

2. Hannah Stitzlein, Myung-Ja K. Han, and Sara R. Benson, “Unraveling Challenges: Rights Statements in Digital Cultural Heritage Collections," Journal of Library Metadata 18, no. 3/4 (2018): 141, https://doi.org/10.1080/1 9386389.2018.1540328.

3. Allison Estell and Laura Saunders, "Librarian Copyright Literacy: Self-Reported Copyright Knowledge Among Information Professionals in the United States," Public Services Quarterly 12, no. 3 (July 2016): 214-27, https://doi.org/10.1080/15228959.2016.1184997; Digital Public Library of America, https://dp.la/ [accessed September 17, 2019].

4. Estell and Saunders, "Librarian Copyright Literacy."

5. Linda Ballinger, Brandy Karl, and Anastasia Chiu, "Providing Quality Rights Metadata for Digital Collections Through RightsStatements.org," Pennsylvania Libraries: Research \& Practice 5, vol. 2 (2017): 145-46, CC-BY, https://doi.org/10.5195/palrap.2017.157.

6. Laura Capell and Elliot Williams, "Implementing RightsStatements.org at the University of Miami Libraries," CC-BY, Journal of Librarianship and Scholarly Communication 6, vol. 1 (2018): 7, https://doi.org/10.7710/21623309.2254 .

7. Capell and Williams, "Implementing RightsStatements.org at the University of Miami Libraries," 2.

8. International Rights Statements Working Group, "Rightsstatements.org White Paper: Recommendations for Standardized International Rights Statements" (2016), https://rightsstatements.org/files/160208recommendations_ for_standardized_international_rights_statements_v1.1.pdf.

9. Europeana, https://www.europeana.eu/portal/en [accessed September 17, 2019].

10. Barney G. Glaser and Anselm L. Strauss, Discovery of Grounded Theory: Strategies for Qualitative Research (Chicago, IL: Aldine Publishing Company, 1967).

11. "Copyfraud ...refers to claiming falsely a copyright in a public domain work." Jason Mazzone, "Copyfraud," New York University Law Review 81, no. 3 (2006): 1028.

12. CixxFive Concepts,LLC v. Getty Images, Inc., No. 2:19-cv-00386-RSL (U.S.D.C. W.D. Wash. May 8, 2019), available at https://assets.documentcloud.org/documents/5784233/Gov-Uscourts-Wawd-270868-1-0.pdf.

13. Bridgeman Art Library v. Corel Corp., 36 F. Supp. 2d 191, 197 (S.D.N.Y. 1999).

14. Nancy Sims, "Rights, Ethics, Accuracy, and Open Licenses in Online Collections: What's 'Ours' Isn't Really Ours," College and Research Libraries News 78, no. 2 (2017): 80.

15. United States Copyright Office, "Orphan Works," https://www.copyright.gov/orphan/ [accessed September 17, 2019].

16100th United States Congress, "Orphan Works Act of 2008” (2008), https://www.congress.gov/bill/110thcongress/house-bill/5889 [accessed September 17, 2019].

17. European Union, Official Journal of the European Union, “Directive 2012/28/EU of the European Parliament and of the Council of 25 October 2012 on Certain Permitted Uses of Orphan Works" (2012), https://eur-lex. europa.eu/legal-content/EN/TXT/?uri=celex:32012L0028 [accessed September 17, 2019].

18. Interview with DPLA Service Hub Respondents, on file with authors.

19. Interview with DPLA Service Hub Respondents, on file with authors.

20. Interview with DPLA Service Hub Respondents, on file with authors.

21. Interview with DPLA Service Hub Respondents, on file with authors.

22. Gaylord v. United States, 595 F.3d 1364 (Fed. Cir. 2010).

23. Gaylord v. United States, 595 F.3d 1364 (Fed. Cir. 2010).

24. Melissa Levine et al., "Finding the Public Domain: Copyright Review Management System Toolkit," CCBY 4.0, https://dx.doi.org/10.3998/crmstoolkit.14616082.0001.001.

25. Interview with DPLA Service Hub Respondents, on file with authors.

26. Deborah Gerhardt, “Copyright Publication: An Empirical Study,” Notre Dame Law Review 87, no. 1 (2011): 163.

27. Greta Bahneman et al., "Rights Review: An Approach to Applying Rights Statements from RightsStatements.org" (2019), http://hdl.handle.net/11299/201539.

28. Society of American Archivists, SAA Intellectual Property Working Group, "Guide to Implementing Rights Statements from RightsStatements.Org" (2016), https://www2.archivists.org/sites/all/files/RightsStatements_IPWG\%20Guidance.pdf.

29. Interview with DPLA Service Hub Respondents, on file with authors.

30. Interview with DPLA Service Hub Respondents, on file with authors. 
31. Interview with DPLA Service Hub Respondents, on file with authors.

32. Interview with DPLA Service Hub Respondents, on file with authors.

33. RightsStatements.org, “Usage Guidelines," https://rightsstatements.org/en/documentation/usage_guidelines.html [accessed September 17, 2019].

34. Creative Commons, "Creative Commons License Properties," https://wiki.creativecommons.org/wiki/ License_Properties [accessed September 17, 2019].

35. Creative Commons, "Creative Commons License Properties."

36. Open Refine, http://openrefine.org/ [accessed September 17, 2019].

37. Interview with DPLA Service Hub Respondents, on file with authors.

38. Interview with DPLA Service Hub Respondents, on file with authors.

39. Interview with DPLA Service Hub Respondents, on file with authors.

40. Interview with DPLA Service Hub Respondents, on file with authors.

41. Interview with DPLA Service Hub Respondents, on file with authors.

42. Interview with DPLA Service Hub Respondents, on file with authors.

43. Peter Hirtle, Cornell University, "Copyright Term and the Public Domain Chart" (2019), https://copyright. cornell.edu/publicdomain [accessed September 17, 2019].

44. Society of American Archivists, SAA Intellectual Property Working Group, "Guide to Implementing Rights Statements from RightsStatements.Org" (2016), https://www2.archivists.org/sites/all/files/RightsStatements_IPWG\%20Guidance.pdf.

45. Gabriel Galson, "RightsStatements.org: Rights Statement Selection Tool” (2018), http://bit.ly/2IVT9SE.

46. College Art Association, "Code of Best Practices in Fair Use for the Visual Arts" (2015), https://www.collegeart.org/pdf/fair-use/best-practices-fair-use-visual-arts.pdf.

47. Bahneman et al., "Rights Review." 